\title{
Research and Practice on the teaching method of computer network course
}

\author{
Liu Li ${ }^{1, a}$, Fu Guangquan ${ }^{2, \text { b }}$, Li GuoQiang ${ }^{3, c}$, Yang Zifen ${ }^{4, d}$ \\ 1,2,3,4 School of Informatics, LinYi University, Linyi 276000, China \\ aemail: xiaoke_1981@126.com, bfuguangquan@lyu.edu.cn \\ cemail: liguoqiang@lyu.edu.cn, dyangzifen@lyu.edu.cn
}

Keywords: computer network; heuristic; case teaching; Protocol; network security

\begin{abstract}
In computer science, the computer network is a lot of curriculum courses, many university computer professional, as a professional required courses, but also is the computer examination for graduate courses in compulsory subjects, in the modern information society of vary from minute to minute, We should improve the students' practice ability, to cultivate students' theoretical knowledge into practical application, but the traditional teaching methods cannot meet the needs of teaching situation of computer network, the paper proposes several new teaching method, such as case teaching method, questioning teaching method, discussion teaching method, These methods are applied to the complicated knowledge points in the computer network, has obtained the good teaching effect.
\end{abstract}

\section{Introduction}

Computer network is a professional required course for computer science majors, is the other part of the professional prerequisite courses, such as the technology of network security, information security, network engineering, network programming, a course is also a computer professional postgraduate courses in compulsory national examination, through the analysis of the design and the postgraduate exam computer network, find related topics in this class lost a lot, perhaps the main cause is not a solid foundation of knowledge, a lot of knowledge to understand, only by rote and lower, these methods and computer network courses are inseparable, that is to say the traditional teaching method has been far cannot meet the current computer the network curriculum needs, development needs to adapt to the new teaching method.

Computer network involving a number of areas of communication technology, computer technology and network security course; briefly introduces the development of network technology, the network structure of the system and concept, focuses on communication technology, computer network technology, Internet network technology and network security etc.. The specific contents there are computer networks, network architecture, physical layer, data link layer, LAN, network interconnection, transport layer, application layer, network security and so on.The students through the computer network to learn, to know the main computer network architecture and the basic working mechanism, grasp the key technology of the LAN and the key technology of Internet, but because of too much knowledge, especially to understand the abstract, and the maneuverability and strong, simply by listening, which is the traditional teaching model has been unable to achieve satisfactory teaching effect, Eventually lead to learn more the more disorderly, more to study hard, cannot use. In order to enhance the effectiveness of teaching, many teachers also improved some teaching methods, try to quote the case, but the case is relatively simple, firmly stuck in the knowledge above, from the reality, is very difficult to understand, cause the teaching effect is not good.

In view of the above characteristics, this paper discusses the application of the heuristic method and the case teaching method in the teaching of computer network, the knowledge of computer network application in reality, can strengthen the students' understanding and analysis of the concepts, enhance the effectiveness of teaching. 


\section{2 case teaching connotation}

The engineering curriculum goal is teaching students to design and complete the project case, analysis of the project is undoubtedly the most direct intuitive, the most direct way of teaching. The teacher according to the specific problem, according to the teaching goal, the representative case of careful and reasonable design, to show the background, problems, solve the problem of meaning, the thinking of specific, realistic problem, but also to the application of the principle of. The use of case teaching is to broaden the students thinking space, increase of computer network curriculum learning interest, to improve students' learning initiative and enthusiasm, but also cultivate their problem-solving thinking ability, judgment ability, decision-making ability and comprehensive ability.

Most of the computer network professional students is to enter the enterprises engaged in network management, maintain the normal operation of the network of the entire firm, but it is in the form of many students to work, practical ability is poor, cannot immediately posts, so companies are not willing to accept to be graduates, this is still with the learned knowledge is not solid, Learned but they cannot use, if the use of heuristic teaching, not only can make the knowledge mastery, can let the students learn to think, to deepen knowledge and understanding.

\section{1 case teaching method in network security}

The network is inseparable from the security, Network security is a very important part in the course of computer network, so in this part will be to combine with case, and the best and the reality of the case to combine the concept of knowledge, explain, and then for example. Image encryption algorithm DES, and RSA, the two algorithms are difficult to understand, DES is a symmetric encryption algorithm, using 16 encryption key, after the 16 round of the cycle of operation to encrypt the information, we often use the QQ chat tools, chat information is encrypted, so this information is encrypted DES encryption algorithm; we have a network of industrial and commercial bank, construction bank, their electronic bank card password and U shield is the use of RSA encryption algorithm, through this example, we deepened the impression, but also enhance the interest in learning, to strengthen the teaching effect.

\section{2 case teaching method in the communication protocol}

On the TCP, UDP of the two protocols, just to explain the theory, students are difficult to understand, if combined with reality, the more easily, the TCP protocol is connection oriented, reliable, full duplex communication protocol, then what is the link for the reliable? For example, A wrote a letter to B, B after 7 days receipt of the letter, and then he returned, and after 7 days to reply letter, so that $\mathrm{A}$ is able to judge this letter has not been tampered with, is complete. My heart is steadfast, but rather a long time, after half a month, is a two-way link, more reliable. The UDP protocol is not reliable, connection oriented protocol. For example, A wrote a letter to B, after 7 days of $B$ received this letter, if the use of the UDP protocol, so he would not need to reply, that is not to determine the content of A has not been modified, still intact? So the establishment of is unreliable, connectionless communication. So the transmission speed of UDP is faster than TCP, in the software development, if the transmission requirement of high efficiency, can use the UDP, if not the pursuit of efficiency, only the pursuit of reliability, transmission can be used TCP. In such a case, the students will understand the basic differences between TCP and UDP. Figure 1 for the TCP and UDP transmission protocol comparison.

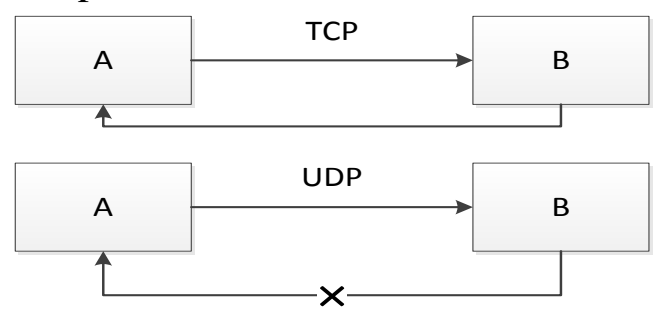

Figure 1 Comparison of TCP and UDP transmission protocol 


\section{The connotation of the heuristic method of teaching}

Most of the computer network professional students is to enter the enterprises engaged in network management, integrated wiring technology, network security technology, network server storage technology, but it is in the form of many students to work, practical ability is poor, cannot immediately posts, so companies are not willing to accept graduates, this is still the knowledge is not solid, it may be, will not use, if the use of heuristic teaching, not only can make the knowledge mastery, but also can let the students learn to think for yourself, and to deepen the understanding of knowledge.

Teaching is the unity of teaching and learning, to teach is to learn, if not, that is meaningless, in the process of teaching, teachers not only teach students to learn, but also to consider the learning, must through the students' independent thinking, but this process does not occur spontaneously, there must be teachers inspiration and guidance, so that students complete the learning task. This is the heuristic teaching.

Teacher give: mainly introduces the basic concepts of computer network course, basic knowledge. At the same time, the scientific learning methods to students, to stimulate students' interest in learning and the effect of passion. Then the immediate questions: about the process if it comes to the already mentioned and used the knowledge learned by asking questions, arouse students' memory, promote their knowledge together, to better understand the new knowledge. Finally, the classroom discussion or debate, it can cultivate students' analysis ability

For example: when explaining the e-mail, can ask to write will put the letter where usually? Who sent to you, is your own? When you receive a letter? Where are you going to take? With such questions, the students will think there will be a post office to help us mail and the mail , go to the e-mail, the post office is forwarding the mail server, when we write a letter on the computer, through the SMTP protocol to the local mail server, he then forwarded to the recipient. The mail server, and then through the POP3 to the recipient, through such inspiration, it is easy to understand.

On the network security, can give students some questions: the reality which used in the network security? Electronic mail, Yu Ebao, Alipay, Tencent QQ account password and so on. These are closely related with us. Then ask these things safe? If not, how to maintain? With these questions the students enjoy learning.

\section{Discussion teaching method}

Discussion teaching method, No matter for students and the teachers are more demanding, the teacher should make full preparations before class, a good topic prepared in advance, if the issue is not good, the students also do not have what can be discussed, in front of the class the teacher only after repeated thinking, access to large amounts of data, it may be unpredictable the problem of effective solutions to appear in the process of discussion. Students are grouped, if the members of the group are not united, not positive thinking, then to discuss something, so it can foster the students "ability of team work, fully prepared is decided" to discuss the prerequisites for teaching can be normal; "Discussion" teaching in many teaching chapter, is to use the knowledge points, as long as the teacher and the students in the class before and after a sufficient knowledge, "discussion" teaching in the face of the boring theory knowledge, can make the subject of lively atmosphere, strengthen the learning effect.

For example: class talked about network design of this piece of contents, teachers can ask such a question in class, and then let the students to discuss: a middle school teaching building 10 classrooms, each classroom with a computer; 2 laboratories, each laboratory with 50 pc machines; an office building: 10 office, each office including 5 PC machines. Floor space of 110 meters. Each building has a reserve, all rooms to reserve distance was less than 90 meters. The 100BASET networking technology, please select the appropriate network device, the transmission medium, the design of network connection. The design of this problem requires a deep understanding of the network, and the protocol is very clear, and have certain ability of comprehensive wiring. Need the usual knowledge accumulation. After the discussion and analysis of the teacher to give a clear 
solution

Then can plan: two building the installation of a VLAN switch, each floor and security support a fiber interface switch. The teaching building and the office building, floor and the main switches with Fibre optic interconnecting, because the floor space is 110 meters, with only the fiber; school information to install Web server, uploading and downloading files can be installed FTP; access to the external INTERNET to install a firewall and security router; monitoring the school operation of the whole network, need to be connected with the capture system in the main switch mirror port.

\section{Conclusion}

This paper analyzes the application of case teaching method, questioning teaching method and the teaching method of discussion, and apply them to the computer network classroom, practice through analysis of examples of the three kinds of teaching methods in the teaching of computer network, the teaching method, can make the students to learn the content about, also has obtained the good teaching effect. Below is the comparison of three kinds of teaching methods. Figure 2 shows the application and practice of the above three kinds of teaching methods in the course of computer network. Through the reaction of teachers and students view, the modern multimedia teaching technology combined with innovative teaching methods more attractive to students, more visibility, but also make the students master the knowledge in the happiness of learning, rather than on the network theory of rote.

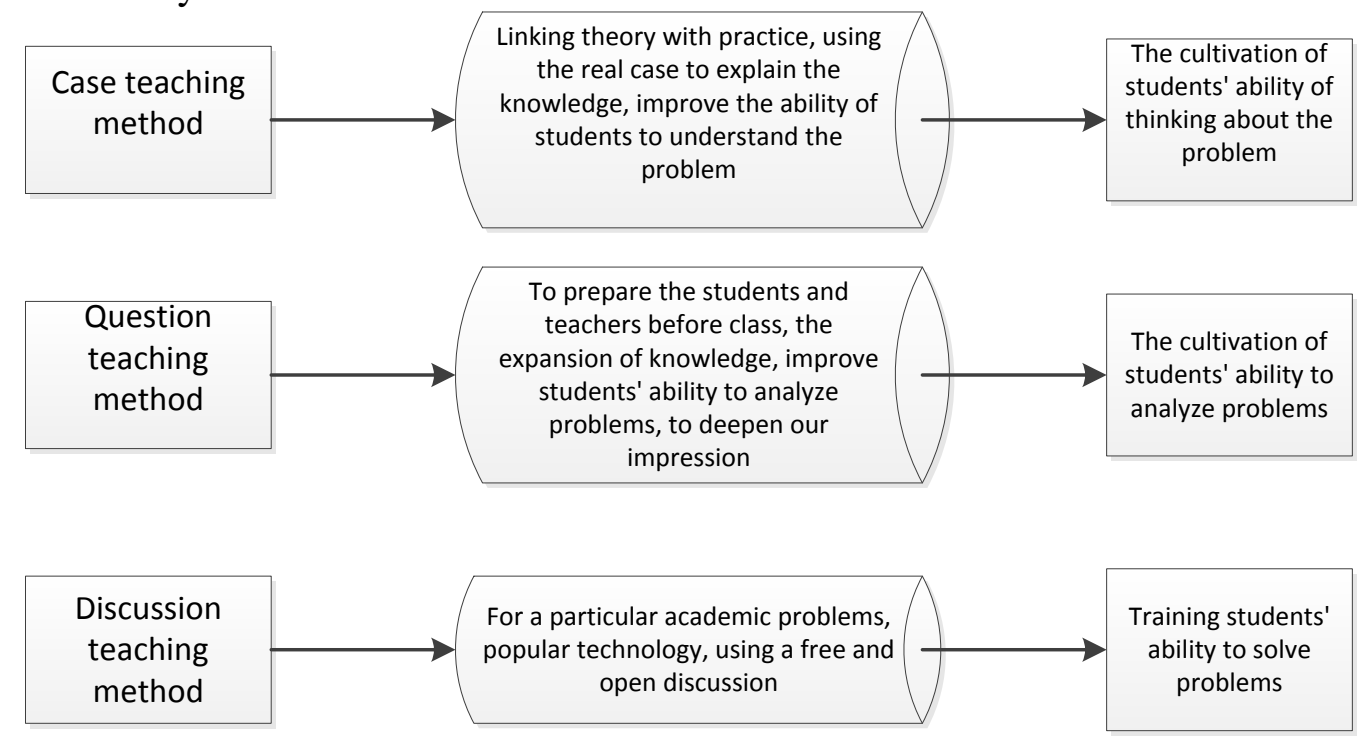

Figure 2 Comparison of three kinds of teaching methods

\section{Acknowledgement}

In this paper, the research was sponsored by the Natural Science Foundation of Shandong Province (Project No. ZR2014FL013).and by the Excellent Course Project of Colleges and Universities in ShanDong Province (Project No. 2013BK109).

\section{References}

[1] Yang Xiaoyan "case" driven "computer network" course teaching reform of computer education, [J]., 2009.18:89-90

[2] pay rock. Case teaching research of [J]. computer software and CD-ROM of computer network application foundation course, 2013.2:252-253

[3] Qiang Zhenping, Chen Xu, di Guangzhi. The teaching method of "computer network" course of [J]. computer, 2013.13:40-42 
[4] Xie Xiren. The computer network [M]. Dalian: Dalian University of Technology press, 2007: 23-354.

[5] cloud Hongyan, Zhigang Zhao, Li Lin, et al. The teaching reform of the course "principles of computer network" to explore the [J]. of modern computer, 2012 (11): 39-42. 